Editorial

\title{
Authors, peer reviewers, and readers: What is expected from each player in collaborative publishing?
}

Fernando FERNANDEZ-LLIMOS iD, Pharmacy Practice 2020 peer reviewers.

Published online: 14-Jan-2021

\begin{abstract}
:
Scholarly publishing is in a crisis, with the many stakeholders complaining about different aspects of the system. Authors want fast publication times, high visibility and publications in high-impact journals. Readers want freely accessible, high-quality articles. Peer reviewers want recognition for the work they perform to ensure the quality of the published articles. However, authors, peer reviewers, and readers are three different roles played by the same group of individuals, the users of the scholarly publishing system - and this system could work based on a collaborative publishing principle where "nobody pays, and nobody gets paid".
\end{abstract}

Keywords:

Cooperative Behavior; Peer Review, Research; Open Access Publishing; Periodicals as Topic

Scholarly publishing is in a crisis. In fact, scholarly publishing is facing several crises simultaneously. Librarians complain about the high journal subscription costs. Project leaders complain about the increasing budgets for article processing charges. Editors complain about the shortage of good peer reviewers. Readers complain about the excessive number of low-quality articles published. Authors complain about the time it takes to get their papers published but also about the comments they receive from peer reviewers. Peer reviewers complain because they are not sufficiently rewarded for their efforts. It seems that we urgently need solutions. However, some of the attempted solutions are only worsening the situation.

When a system is under as much stress as the scholarly publishing system is, an in-depth analysis is necessary. Simple and quick solutions will probably not reduce the tensions and may lead to irrevocable damage to the system. Before starting a systems analysis, one must consider if the product or service is necessary and useful. Should we keep publishing articles as a way to disseminate research? Since as early as 1665 , scientific societies and scientists from different areas have privileged the articles published in scientific journals as the prime method for disseminating their knowledge. Books can be an alternative to scientific articles, and in some fields, they are, but in the pure and applied sciences, to use Kuhn's terminology, prefer shorter, more specific, and more rapidly disseminated media. ${ }^{1}$ Communication through conferences is another alternative method, but traveling to conferences is highly costly, and the abstracts - what is disseminated outside the conference - are probably too short to provide sufficient information for other researchers to learn from. Scientific articles, previously printed and stored in libraries, are now globally available at the moment they are posted to the journal webpage and can be any length necessary to sufficiently detail the research performed and the results found. Videos and podcasts may be a real alternative to consider, but they share many of the characteristics and requirements of published articles. Therefore, we could state that, at least for some time yet, scientists will use scientific articles as the main method to disseminate their research results.

The first step in systems analysis should be identifying the players - the system stakeholders. ${ }^{2}$ That is to say, we must determine who the owners and users are. For centuries, the owners and users of scholarly publications were the same group of individuals: scientists and researchers grouped in scientific societies. However, although some things have changed, identifying the owners is easy: they have legal documents that demonstrate their ownership. Where we are probably making a major mistake is on the user side, specifically on the level of importance we attribute to users.

If scientific journals are channels for disseminating the results of research in the form of scientific articles, the real users of these communication systems are the those who use and value their content and who are impacted by what is presented, this is to say, the readers. Unfortunately, the scholarly publishing system is more focused on those who are attempting to communicate their research and need to demonstrate their value during their periodical performance assessments: the authors. This perverse inversion of the roles between producer and consumer is the basis of many of the problems that the scholarly publishing system is facing.

A clear example of this problematic situation is confusion about the concept of open access. While every reasonable person should be in favor of the "world-wide electronic distribution of the peer-reviewed journal literature and completely free and unrestricted access to it by all scientists, scholars, teachers, students, and other curious minds", the current situation has warped this idea. ${ }^{3}$ One might first think about the corporate responsibility of the owners that

Fernando FERNANDEZ-LLIMOS. PhD, MPharm, MBA. Editor-in-

chief, Pharmacy Practice. Center for Health Technology and

Services Research (CINTESIS), Laboratory of Pharmacology,

Faculty of Pharmacy, University of Porto. Porto (Portugal).

fllimos@ff.up.pt

Pharmacy Practice 2020 peer reviewers. 
would prompt them to provide the necessary resources to sustain free, open access scientific journals. This is the way that many journals are published (e.g., Pharmacy Practice and more than 11,000 journals listed in DOAJ https://doaj.org/). Other scientific or professional societies do not believe that publishing a journal falls under the scope of their corporate responsibility and charge subscription fees for nonmembers interested in accessing the articles. Obviously, it is understandable that for-profit companies publish journals as part of their business model and charge subscription fees: in a market economy, they must run a valuable journal to obtain payments from readers or their institutions.

However, only in a perverse situation such as the one we are suffering in the scholarly publication system can one imagine a publishing model that, under the guise of open access, charges authors to get their articles published. It seems that article processing charges, the APCs, are not included in the idea of "free and unrestricted access to it by all scientists". In a healthy situation, why would authors pay APCs to share their knowledge and their research results? In a healthy world, one can walk to the podium or climb onto a soap box and give a speech for free. If the speech is relevant, the speaker will soon have a crowd around. Only in a perverse situation where the main user is not the reader but the author can one understand a system focused on the author and the merit of publishing an article, regardless of whether there is anyone near the soap box. When the milestone is publishing an article, not having one's article read, it makes sense that authors must pay for publishing. However, let us be honest: this is not "open access"; it is a different business model for for-profit journals. ${ }^{4}$ This business model is also the foundation for predatory publishers, a term with a complex definition. ${ }^{5,6}$ Perhaps one day, someone will reconsider the low value added by the APC-open access publishing model and the consequences it has for research environments. ${ }^{7}$

Pharmacy Practice was created under the collaborative publishing principle, which can be stated as "nobody pays, and nobody gets paid". Pharmacy Practice wants to be the soap box onto which researchers can climb to disseminate their research results while still maintaining the highest publication standards. The term collaboration -joint work on an activity or project - may have not always been correctly understood. In our analysis of Pharmacy Practice's publishing system, we understand the 'user' to be a single person with three alternating roles: the author role, the reviewer role, and the reader role. When performing each of the three roles, users have different things in mind:

- When users play the author role, they want to have their paper published quickly in a high-impact, high-visibility journal.

- Users playing the reader role want to have free access to high-quality papers that present the results of research performed following the best research practices and are published following the highest standards of scientific reporting and publishing, which includes the contributions of rigorous peer reviewers.

- Users playing the peer reviewer role want to contribute only to high-quality papers close to their area of interest and expertise and obtain some kind of public recognition of their work.

In a collaborative publishing system, users should consider not only what they want when they perform one of the roles but also how they can act in their current role to provide to others the things they want when performing another role.

In previous editorials, Pharmacy Practice acknowledged the crucial role peer reviewers have in scholarly publications. ${ }^{5,8}$ Four years ago Pharmacy Practice initiated a method for publicly recognizing peer reviewers by publishing the first editorial including all the reviewers who had completed a review in the past year as collaborators. However, we also described the long and winding process required to ensure three reviewers per paper. ${ }^{9}$ During 2020, Pharmacy Practice published 82 articles and sent 706 invitations to researchers participate as peer reviewers, 19 of which bounced back as undeliverable due to email address errors. Of the remaining 687 invitees, 323 (47.0\%) never responded, 136 (19.8\%) declined the invitation because they were busy, $12(1.7 \%)$ declined due to the manuscript being outside their area of expertise, and 1 declared a conflict of interests (18 were in progress at time this editorial was written). Three of those who accepted the task never finished the review, and the rest provided their comments within 18 days (SD 13). Their collaboration allowed us to reduce the time from submission until the first response to authors to approximately 50 days. We know that users playing the author role are demanding fewer delays in this stage of the publication process. Therefore, one of the components of the collaborative publishing principle is as follows:

\section{"The more manuscripts you agree to review, the faster you'll have your own manuscripts published".}

The number of articles published yearly grows nonstop. Some authors believe that the system is overtaxed by so many papers. However, there are approximately 8 million researchers around the world who want to disseminate their findings. ${ }^{10}$ If the findings are relevant, someone playing the reader role will be interested in the article. A relevant study does not necessarily mean a large or expensive study. Pharmacy Practice published a guide to help determine if a potential article is relevant for an international audience. ${ }^{11}$ So, why are researchers compelled to publish what they probably know is an irrelevant article? Again, the scholarly publishing system has been corrupted and converted into a performance-assessment system. In this perverted system, importance is placed on publishing papers regardless of whether they are ever read. Therefore, when users playing the reader role are annoyed by irrelevant articles, they should consider that other users playing the author role are happy because they have achieved the goal of publishing their article. Therefore, another component of the collaborative publishing principle could be stated as:

"The more trash you put into the system, the more trash you will have to consume". 
Finally, one might believe that authors should only contribute relevant and high-quality papers, but this is a minimum requirement to be considered and accepted as an author. To have relevant and high-quality manuscripts published, we need other authors to play the reviewer role and deliver high-quality reviewer reports with constructive comments that will contribute to enhancing the quality of the manuscript. ${ }^{12}$ As a means to reduce the delay between submission and the first decision, Pharmacy Practice will consider this component of the collaborative publishing principle as a basic requirement for any submitting author.

Authors also want to publish their articles in a high-impact journal (i.e., with high Impact Factor or CiteScore). However, sometimes authors forget that impact metrics are calculated based on the number of citations received by the articles published in a given journal. They also forget that other users playing the author role produce these citations. The field of pharmacy practice deserves a case study investigating two detrimental behaviors that minimize the visibility and impact of this field within other biomedical fields. First, pharmacy practice researchers tend to believe that important studies have to be published in journals outside the pharmacy practice area to increase the visibility of their study; second, pharmacy practice researchers tend to believe that citing articles from journals outside the pharmacy practice area increases the value of their own article. The first consideration not only is inherited from the times when journals were physically printed and one needed to obtain the printed journal to access articles but also has several negative outcomes associated with it. Peer reviewers from other scientific areas will contribute their expertise but may lack knowledge of the specific nuances of pharmacy practice. The lack of standardized terminology frequently described in pharmacy practice and the limited number of pharmacy-specific Medical Subject Headings (MeSH) are obvious consequences of the lack of opportunity for pharmacy practice researchers to act as peer reviewers and contribute to improving their colleagues' manuscripts. ${ }^{13,14}$ Additionally, if an article published outside the pharmacy practice area is truly high-quality and becomes a highly cited article, its authors will have contributed to increasing the impact metrics of the other field, where they probably have lower chances of publishing their next article. The second consideration, preferentially citing articles from other areas, is the origin of the Matthew effect, which is causing the pharmacy practice field to be the poor becoming poorer. Conversely, citing articles from the pharmacy practice field increases the impact metrics of the area in which pharmacy practice researchers are more likely to be able to publish future articles. Finally, another component of the collaborative publishing principle can be stated as:

"The more you take care of your scientific area, the more your scientific area will take care of you".

At this point, it is important to clearly state that Pharmacy Practice has never and will never obligate citing a given article or a given journal in order to get a submitted article published. Pharmacy Practice believes that when a peer reviewer suggests an article to cite, the reviewer is only commenting about a potential improvement of the reviewed article, and citing that article is never an obligation for the submitting authors. Forcing authors to comply with any such comments would be an unethical and punishable behavior.

In summary, what Pharmacy Practice expects from potential authors is that they understand the philosophy behind the journal, especially the collaborative publishing principle, which will allow them to publish in a high-quality, widely indexed journal for free. Specifically, authors should remember that to have a manuscript published, they need other authors to act as peer reviewers and other authors to read and cite their article. At the end of the day, all the users in the scholarly publishing system are part of the same group of individuals.

\section{Updates to the Instructions for Authors}

With the aim of facilitating submitting authors' obligations, a few modifications will be implemented into Pharmacy Practice's instructions for authors.

The number of authors that should be listed in a bibliographic reference is a controversial subject. Different citation styles use different numbers. Until 2021, Pharmacy Practice permitted up to 25 authors in each reference, with the remaining cited as 'et $a l^{\prime}$. With the massive adoption of persistent interoperable identifiers, especially the digital object identifier (DOI) system, the rules of citation styles should be reconsidered. In the past, rigorous attendance to a specific style facilitated the identification of the article cited. Since the implementation of DOI, one can use only the DOI as a univocal identifier of the cited article, the rest of the elements being used only as content that is comprehensible to humans. Thus, Pharmacy Practice has adopted AMA style since 2021, which calls for listing three authors followed by 'et $a l^{\prime}$, if more than six authors exist. It is important to highlight that AMA style includes the DOI at the end of each citation. To facilitate the citation process even more, since PubMed restyled its display content, authors using manual citation systems can copy/paste the complete text of the reference in AMA style from the "Cite" feature of PubMed.

In 2020, two changes to the instructions for authors were implemented and were inadvertently omitted from the first issue's editorial. The first consisted of limiting each author to one listed affiliation. The APA 6 Manuscript Preparation Guidelines defines an affiliation as "the location where the author or authors were when the research was conducted, which is usually an institution". ${ }^{15}$ In the current perverse scholarly publication system, the author affiliations declared in an article serve to calculate institutional rankings by identifying which institution can take credit for the author's work. However, the affiliation should represent not only the institution the researchers report to and abide by the regulations but, more importantly, the institution where editors must report any confirmed scientific misconduct and would expect disciplinary measures to follow. ${ }^{16}$ Unfortunately, declaring fake affiliations is a widespread practice. However, it is also 
common for authors temporarily working or studying at prestigious institutions to declare, in addition to their permanent institution, their temporary institution. Pharmacy Practice expects each author to reports only one affiliation, and this should correspond to the institution with which the researcher has a regulated relationship.

The second modification implemented in 2020, also in relation to authors' institutional responsibility, was the mandatory translation of authors' affiliations into English. English is used as a lingua franca in scientific communication, which is why in 2006 Pharmacy Practice adopted English as the only language of publication. As a counterargument to this initiative, one could state that institution names are brand names and should not be translated because institution names are easily identified (e.g., Universidade, Université, Università, Universiteit, Universitas, Universiti). However, again, this is an attempt to remedy the perverted scholarly publishing system, because a reader should always be able to identify the institution behind the author writing the article. As editors, we face the issue of where we should set the limits of the easy identification? (Table 1). Jaamacadda, Egyetem, Университет, इससे संबंधित विश्वविद्यालय, الم, and 大學 may be less easily understood by many readers. Thus, drawing lines regarding which institutions would require translation into English and other institutions that could use their vernacular names would be unacceptably discriminatory. That is why all the institution names mentioned in affiliations of articles published in Pharmacy Practice must be translated into English.

\begin{tabular}{|c|c|}
\hline \multicolumn{2}{|l|}{ Block \#1: Institutions with slightly different words easily identified } \\
\hline Universidade do Porto & University of Porto \\
\hline Université de Paris & University of Paris \\
\hline \multicolumn{2}{|l|}{ Block \#2: Institutions with some words that could be misunderstood } \\
\hline Vrije Universiteit Brussel & Free University of Brussels \\
\hline Università degli Studi di Camerino & University of Camerino \\
\hline Università degli Studi Roma Tre & University of Rome 3 \\
\hline Universiti Sains Malaysia & University of Sciences Malaysia \\
\hline Uniwersytet Jagielloński & Jagiellonian University \\
\hline Københavns Universitet & University of Copenhagen \\
\hline Universitas Padjadjara & Padjadjaran University \\
\hline \multicolumn{2}{|l|}{ Block \#3: Institutions with unintelligible names for non-native audience } \\
\hline Rheinisch-Westfälische Technische Hochschule Aachen & Technical University of Aachen, North Rhine-Westphalia \\
\hline Московский государственный университет & Moscow State University \\
\hline Медицински университет в София & Medical University in Sofia \\
\hline 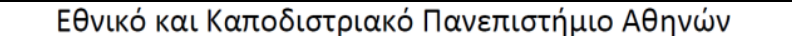 & National and Kapodistrian University of Athens \\
\hline جامعة القاهرة & Cairo University \\
\hline 東京大学 & University of Tokyo \\
\hline
\end{tabular}

\section{Pharmacy Practice 2020 peer reviewers}

\section{Two reviews:}

Edita Alili-Idrizi, State University of Tetovo, Macedonia Mohamed E. Amin, Beirut Arab University, Lebanon Zubin Austin, University of Toronto, Canada Sarah J. Billups, University of Colorado, United States Afonso M. Cavaco, University of Lisbon, Portugal Jack C. Collins, University of Sydney, Australia Jaqueline K. Eserian, Federal University of Sao Paulo, Brazil Andi Hermansyah, Airlangga University, Indonesia Kristin K. Janke, University of Minnesota, United States Jennie B. Jarrett, University of Illinois at Chicago, United States

Pascale Salameh, Lebanese University, Lebanon leva Stupans, University of New England, Australia

\section{One review:}

Derar H. Abdel-Qader, University of Petra, Jordan Dania Abunaser, Al-Balqa'a Applied University, Jordan Rasaq Adisa, University of Ibadan, Nigeria Wuraola Akande-Sholabi, University of Ibadan, NIgeria Ahmad Al-Azayzih, Jordan University of Science \& Technology, Jordan

Selamawit Alemayehu, University of Colorado, United States Hamzah T. Alzubaidi, University of Sharjah. United Arab Emirates

Johanna Aponte-González, Universidad Nacional de Colombia, Colombia

Justin R. Arnall, Levine Cancer Institute, United States Beata Bajorek, University of Technology, Sydney, Australia David Balayssac, CHU Clermont-Ferrand, France Jean-Didier Bardet, University of Grenoble Alpes, France Marie Barnard, University of Mississippi, United States Susanne Barnett, University of Wisconsin, United States Iman A. Basheti, Applied Science University, Jordan Arcelio Benetoli, Ponta Grossa State University, Brazil Shelby A. Bennett, Cherokee Main Street Pharmacy, United States

Emily Black, Dalhousie University, Canada

Timothy J. Bloom, Campbell University, United States

Aline F. Bonetti, Federal University of Parana, Brazil 
Helena H. Borba, Federal University of Parana, Brazil

Daniel Bradley, Medical University of South Carolina, United States

Pamela J. Bradshaw, University of Western Australia, Australia

Cecilia Brata, University of Surabaya, Indonesia Jovana Brkic, Charles University, Czech Republic David Brumbaugh, University of Colorado, United States

Paulo Caceres Guido, JP Garrahan Pediatric Hospital, Argentina

Cathal Cadogan, Royal College of Surgeons, Ireland Jeffrey Cain, University of Kentucky, United States Ron Carico, Marshall Pharmacy, United States

Manuel J. Carvajal, Nova Southeastern University, United States

Margarida Castel-Branco, University of Coimbra, Portugal Damien Cateau, University of Geneva, Switzerland Jagjot Chahal, St Bartholomew's Hospital, United Kingdom Vincent Chan, RMIT University, Australia

Theresa L. Charrois, University of Alberta, Canada Ejaz Cheema, University of Birmingham, United Kingdom Timothy F. Chen, University of Sydney, Australia Eun K. Chung, Kyung Hee University, South Korea Emily J. Cicali, University of Florida, United States Peter Clap, University of Texas, United States Kevin Clayton, University of New England, Australia Peter M. Clifton, University of South Australia, Australia Lisa B. Cohen, University of Rhode Island, United States Kevin Cowart, University of South Florida, United States Ashley S. Crumby, University of Mississippi, United States Marcílio S. Cunha-Filho, University of Brasília, Brazil Dalia Dawoud, Cairo University, Egypt

Thomas Delate, University of Colorado, United States Rhian Deslandes, Cardiff University, United Kingdom Sarah Dineen-Griffin, Charles Sturt University, Australia Mark Dunnenberger, NorthShore University Health System, United States

Iffat Elbarazi, Abu Dhabi University, Dibai

Abubaker I. Elbur, Imam Abdulrahman Bin Faisal University, Saudi Arabia

Abigail Elmes, University of Illinois, United States

Karen B. Farris, University of Michigan, United States

Tanja Fens, University of Groningen, Netherlands

Cathy Ficzere, Belmont University, United States

Brooke D. Fidler, Long Island University, United States

Joseph L. Fink, University of Kentucky, United States

Rhianna M. Fink, University of Colorado, United States

Paul Forsyth, NHS Greater Glasgow \& Clyde, United Kingdom

Jaheeda Gangannagaripalli, University of Strathclyde, United Kingdom .

Beate H. Garcia, University of Troms $\varnothing$, Norway

Victoria Garcia Cardenas, University of Technology, Sydney, Australia

Marise Gauci, University of Malta, Malta

Shadi F. Gharaibeh, Jerash University, Jordan

Kathrine Gibson Smith, University of Aberdeen, United Kingdom

Alexandria E. Gochenauer, Purdue University, United States

Nina Griese-Mammen, Federal Union of German Associations of Pharmacists, Germany

Mara P. Guerreiro, Egas Moniz Higher Institute of Health Sciences, Portugal

Kyrillos Guirguis, PharmaceuCare, Australia

Trine Gulholm, NSW Health Pathology, Australia

Genevieve Hale, Nova Southeastern University, United States

Souheil Hallit, Holy Spirit University of Kaslik, Lebanon

Souheil Hallit, INSPECT-LB, Lebanon

Tora Hammar, Linnaeus University, Sweden

Hussein Haruna, University of Hong Kong, China

Mohamed A. Hassali, Universiti Sains Malaysia, Malaysia

Maria T. Herdeiro, University of Aveiro, Portugal
Evelyn R. Hermes-DeSantis, Robert Wood Johnson University Hospital, United States

Ana L. Hincapie, University of Cincinnati, United States

Samantha Hollingworth, University of Queensland, Australia

Rabia Hussain, Universiti Sains Malaysia, Malaysia

Osama H. Ibrahim, University of Sharjah, United Arab Emirates

Adriane N. Irwin, Oregon State University, United States

Katia Iskandar, Lebanese International University, Lebanon

Idongesit L. Jackson, University of Uyo, NIgeria

Arianit Jakupi, University for Business and Technology, Kosovo

Susanne Kaae, University of Copenhagen, Denmark

Sofia Kälvemark Sporrong, University of Copenhagen, Denmark

Maram G. Katoue, Kuwait University, Kuwait

Margaret Kay, University of Queensland, Australia

Viviane Khalil, Monash University, Australia

Eliška Kolmanová, University of Veterinary and

Pharmaceutical Sciences Brno, Czech Republic

Andries S. Koster, Utrecht University, Netherlands

Milena Kovačević, University of Belgrade, Serbia

Yoshiki Kusama, Disease Control and Prevention Center, Japan

Giuseppe La Torre, Sapienza University of Rome, Italy

Marta Lavrador, University of Coimbra, Portugal

Katherine A. Lawson, El Paso Texas VA, United States

Luana Lenzi, Federal University of Parana, Brazil

Leticia Leonart, Federal University of Parana, Brazil

Nancy J. Lewis, University of Michigan, United States

Chelsey Llayton, Virginia Commonwealth University, United States

Jason S. Loo, Taylor's University, Malaysia

José Julián López, Universidad Nacional de Colombia, Colombia

Karen Luetsch, University of Queensland, Australia

Elyse A. MacDonald, University of Utah Health Care, United States

Mark J. Makowsky, University of Alberta, Canada

Abdulaziz Malik, Boston Medical Center, United States

Andrea Manfrin, University of Central Lancashire, United Kingdom

Efi Mantzouranie, Cardiff University, United Kingdom

Craig A. Martin, University of Kentucky, United States

Nancy A. Mason, University of Michigan, United States

Tressa McMorris, Roseman University of Health Sciences, United States

Melissa S. Medina, University of Oklahoma, United States

Angelita C. Melo, Federal University of São João Del-Rei, Brazil

Simone A. Mendoça, Federal University of Minas Gerais, Brazil

Ashley H. Meredith, Purdue University, United States

Markus Messereli, University of Basel, Switzerland

Jason Min, University of British Columbia, Canada

José J. Mira, Sant Joan d'Alacant Health Service, Spain

Leticia R. Moczygemba, University of Texas, United States

Rebekah Moles, University of Sydney, Australia

Jean Moon, University of Minnesota, United States

Gina D. Moore, University of Colorado, United States

Mona Mostaghim, University of Technology Sydney, Australia

Fiona Needleman, NHS Greater Glasgow and Clyde, United Kingdom

Rosemary Newham, University of Strathclyde, United Kingdom

Marcel Nogueira, University of São Paulo, Brazil

Pauline Norris, University of Otago, New Zealand

Marina Odalović, University of Belgrade, Serbia

Verónica V. Olavarría, Universidad del Desarrollo, Chile

Stefano Omboni, Italian Institute of Telemedicine, Italy

Kanayo P. Osemene, Obafemi Awolowo University, NIgeria

Ha Eun (Leena) Park, University of Colorado, United States 
Gregory Peterson, University of Tasmania, Australia Ann M. Philbrick, University of Minnesota, United States Carla M. Pires, University of Lisbon, Portugal Patricia Quintana-Barcena, University of Geneva, Switzerland Andrew Radley, Kings Cross Hospital, United Kingdom

Rotana M. Radwan, Virginia Commonwealth University, United States

Adriano M. Reis, Federal University of Minas Gerais, Brazil Olaf Rose, impac2t, Germany

Jackie Roseleur, Flinders University, Australia

Inajara Rotta, Federal University of Parana Teaching Hospital, Brazil

Daniel Sabater-Hernandez, University of Granada, Spain

Sajal K. Saha, Monash University, Australia

Fahad Saleem, University of Baluchistan, Pakistan

John Saunders, University of Utah, United States

Nathalie Sayegh, Lebanese University, Lebanon

Ellen M. Schellhase, Purdue University, United States

David M. Scott, North Dakota State University, United States

Robert Seabury, Upstate University Hospital, United States

Andrew Stafford, Curtin University, Australia

Derek Stewart, Qatar University, Qatar

Bruce Sunderland, Curtin University, Australia

Judith Strawbridge, Royal College of Surgeons, Ireland
Damian Świeczkowski, Medical University of Gdansk, Poland Meng-Wong Taing, University of Queensland, Australia Fernanda S. Tonin, Federal University of Parana, Brazil Neusa F. Torres, Higher Institute for Health Sciences, Mozambique

Jessica S. Triboletti, Butler University, United States Pasitpon Vatcharavongvan, Thammasat University, Thailand Veronica Vernon, Butler University, United States Daisy Volmer, University of Tartu, Estonia

Onanong Waleekhachonloet, Mahasarakham University, Thailand

Kyle J. Wilby, University of Otago, New Zealand Astrid Wiens, Federal University of Parana, Brazil Matthew J. Witry, University of lowa, United States Daniel M. Witt, University of Utah, United States Payom Wongpoowarak, Prince of Songkla University, Thailand Sally G. Yaacoub, Lebanese University, Lebanon

Ismaeel Yunusa, Massachusetts College of Pharmacy and Health Sciences, United States

Romana Zelkó, Semmelweis University, Hungary Kristin Zimmerman, Virginia Commonwealth University, United States

\section{References}

1. Kuhn TS. The Structure of scientific revolutions. Chicago: University Press; 1962.

2. Whitten JL, Bentley LD, eds. Systems analysis and design methods, 7th ed. New York: McGraw-Hill; 2007. ISBN: 10: 0 07-305233-7

3. Read the Budapest Open Access Initiative. https://www.budapestopenaccessinitiative.org/read (accessed Jan 3, 2021).

4. Fernandez-Llimos F. Collaborative publishing: the difference between 'gratis journals' and 'open access journals'. Pharm Pract (Granada). 2015;13(1):593. https://doi.org/10.18549/pharmpract.2015.01.593

5. Fernandez-Llimos F. Open access, predatory publishing and peer-review. Pharm Pract (Granada). 2014;12(1):427. https://doi.org/10.4321/s1886-36552014000100001

6. Predatory journals: no definition, no defence. https://www.nature.com/articles/d41586-019-03759-y?sf225811500=1 (accessed Jan 3, 2021).

7. Van Noorden R. Open access: The true cost of science publishing. Nature. 2013;495(7442):426-429 https://doi.org/10.1038/495426a

8. Fernandez-Llimos F; Pharmacy Practice 2017 peer reviewers. Scholarly publishing depends on peer reviewers. Pharm Pract (Granada). 2018;16(1):1236. https://doi.org/10.18549/pharmpract.2018.01.1236

9. Fernandez-Llimos F; Pharmacy Practice 2018 peer reviewers. Peer review and publication delay. Pharm Pract (Granada). 2019;17(1):1502. https://doi.org/10.18549/pharmpract.2019.1.1502

10. ORCID 2019 Annual Report. https://orcid.figshare.com/ndownloader/files/22061544 (accessed Jan 3, 2021).

11. Fernandez-Llimos F. Is my paper relevant for an international audience?. Pharm Pract (Granada). 2020;18(2):1924 https://doi.org/10.18549/pharmpract.2020.2.1924

12. Fernandez-Llimos F, Salgado TM, Tonin FS; Pharmacy Practice 2019 peer reviewers . How many manuscripts should peer review per year?. Pharm Pract (Granada). 2020;18(1):1804. https://doi.org/10.18549/pharmpract.2020.1.1804

13. Gernant SA, Bacci JL, Upton C, et al. Three opportunities for standardization: A literature review of the variation among pharmacists' patient care services terminology. Res Social Adm Pharm. 2020;16(6):766-775. https://doi.org/10.1016/j.sapharm.2019.08.034

14. Fernandez-Llimos F, Salgado TM. Standardization of pharmacy practice terminology and the Medical Subject Headings (MeSH) [published online ahead of print, 2020 Jul 8]. Res Social Adm Pharm. 2020; [ahead of print]. https://doi.org/10.1016/j.sapharm.2020.07.005

15. Bachelet VC, Uribe FA, Díaz RA, et al. Author misrepresentation of institutional affiliations: protocol for an exploratory case study. BMJ Open. 2019;9(2):e023983. https://doi.org/10.1136/bmjopen-2018-023983

16. Fernandez-Llimos F. Pharmacy Practice suffered a plagiarism case. Pharm Pract (Granada). 2012;10(1):1-2. https://doi.org/10.4321/s1886-36552012000100001 